\title{
PROBLEMATIZANDO OS PCNEM + PARA A ATIVIDADE DOCENTE DE FILOSOFIA
}

\section{TO PROBLEMAZE THE PCNEM+ FOR THE PHILOSOFY TEACHING}

\author{
Edson JACINSKI* \\ José Rogério VITKOWSKI**
}

\begin{abstract}
Resumo: O presente texto estabelece um diálogo com os PCN+ e explora a relação entre filosofia, educação e ensino, a partir da prática educacional auto-reflexiva dos autores, fecundada pela perspectiva teórica de Deleuze e Felix Guatari. Pretende-se aqui explicitar alguns dos principais sentidos da atividade filosófica na educação formal - secundária - buscando-se elementos que possibilitem revitalizar a atividade docente. Desse modo, a abordagem se dá a partir da perspectiva do ensino, problematizando posturas didático-pedagógicas e as ambigüidades da inserção institucional da Filosofia como disciplina, sem descurar da necessária demarcação epistêmica. A abordagem de tais questões opera-se a partir da perspectiva da metarreflexão sobre a própria filosofia, sugerindo-se a superação do ensino da Filosofia como atividade meramente contemplativa, reflexiva ou comunicativa e propondo-se pensá-la na ótica deleuziana como criação de conceitos, o que pode permitir uma ressignificação da tradição filosófica, redimensionando criticamente o olhar sobre o cotidiano.
\end{abstract}

Palavras-chave: Educação. Filosofia. Deleuze.

Abstract: The present text establishes a dialogue with the PCN+ and explores the relation among philosophy,

\footnotetext{
* Mestre em Tecnologia pela UTFPR. Professor da Universidade Tecnológica Federal do Paraná, Campus Ponta Grossa. E-mail: ejacinski@uol.com.br

** Mestre em Educação pela UEPG. Professor da Universidade Estadual de Ponta Grossa. E-mail: jrvitkowski@uol.com.br
} 
Problematizando os PCNEM+ para a atividade docente de Filosofia

education and teaching from the authors' self-reflexive and educational practice, conceived on the theoretical perspective of Deleuze and Felix Guatari. The purpose of this work is to make explicit some of the main meanings of the philosophical activity in the formal education, searching for elements that make possible the revitalization of the teaching activity. Thus, the approach occurs from the teaching perspective, questioning the didactic-pedagogical attitudes and the ambiguities of the institutional insertion of Philosophy as a subject, without nevertheless, disregarding the necessary epistemological delimitation. The approach of such matters is taken from a meta-reflection investigation over the own philosophy, suggesting to surpass the teaching view of Philosophy as a merely contemplative, reflexive or communicative activity. It also proposes to think of Philosophy within the Deleuzian thought as a creation of concepts that allows a re-meaning of the philosophical tradition as well as to dimension again the quotidian in a critical view.

Keywords: Education. Philosophy. Deleuze.

Em face da recente legitimação da Filosofia nos espaços-tempo educacionais, urge problematizar o seu ensino. Tal questão abre um universo de problemas que vão das diversas concepções de Filosofia às metodologias possíveis, aos modelos pedagógicos a serem desenvolvidos, à formação do professor, aos materiais didático-pedagógicos. Neste texto, buscar-se-á um diálogo com os Parâmetros Curriculares Nacionais do Ensino Médio (PCNEM), na sua versão mais recente, denominada PCNEM+, confrontando-os com a perspectiva dos filósofos Gilles Deleuze e Felix Guattari ${ }^{1}$, que podem contribuir significativamente no que tange à própria noção de Filosofia e, por conseguinte, de seu ensino. Esse trabalho se nutre ainda com a prática pedagógica dos autores no ensino de Filosofia em nível médio e superior, prática essa que se dá no cotidiano de sala de aula, propiciando encontros fecundos, mas também tensos, densos e até contraditórios, com a

${ }^{1}$ Utilizar-se-á neste texto o termo "perspectiva deleuziana" para referir-se ao pensamento desses filósofos. 
pluralidade dos sujeitos educacionais.

Como reconhece o documento PCNEM+, para se pensar o ensino da Filosofia no Ensino Médio é necessário perceber a sua especificidade em relação às outras disciplinas, pelo próprio caráter peculiar do exercício do filosofar. Como salienta Gallo, "pensar o exercício da filosofia no ensino médio brasileiro neste início de século vinte e um exige esforço e abertura à diversidade" (apud FÁVERO, 2002, p.189). Essa abertura vem, na realidade, acontecendo há muito tempo, pois a diversidade está presente nos vinte e cinco séculos de produção filosófica, que preconizam diferentes finalidades, pretensões e estilos da atividade filosófica. Nesse sentido, a própria conceitualização da Filosofia é problemática e, na verdade, irá revelar a(s) linha (s) epistemológica (s) e metodológica (s) do professor. Essa escolha deve ser cuidadosa e pedagogicamente pensada, para que o exercício filosófico não leve a práticas educativas que, em vez de estimular o educando, acabem dificultando ou afastando os jovens desse contato com o filosofar. Para tanto, tal escolha deve evitar dois riscos graves: o de se cair no dogmatismo que absolutiza a perspectiva teórica adotada, ou o de se cair no relativismo que legitima, sem critérios, qualquer perspectiva teórica. Deve, portanto, haver um esforço do professor em ser "transparente", deixando claro aos alunos que se trata de "uma" perspectiva e não "da" perspectiva.

Assim, torna-se importante essa definição para que se possa estabelecer um ponto de referência para um encontro dialógico produtivo com as diferentes percepções da Filosofia e do filosofar. Também cabe ressaltar que é pertinente a vinculação da Filosofia à área das "Ciências Humanas e suas Tecnologias", feita pelos PCNEM, mas insuficiente, pois os interesses múltiplos e amplos do filosofar e da Filosofia extrapolam o campo das Ciências Humanas. A Filosofia certamente tem muitas afinidades com as Ciências Humanas, mas, sem dúvida, também irá interagir com as produções científicas e culturais das outras áreas mencionadas nos PCNEM: "Ciências da natureza, Matemática e suas Tecnologias" e "Códigos e Linguagens e suas Tecnologias".

Tais considerações levam a enfatizar a problematicidade da própria configuração do campo do saber e das competências a serem desenvolvidas no curso de Filosofia no Ensino Médio, salientado pelos PCNEM+ (2006, p. 41- 42):

Estabelecer o que o aluno deve conhecer e que competências desenvolver no curso de Filosofia no Ensino Médio configura uma 
Problematizando os PCNEM+ para a atividade docente de Filosofia

tarefa a ser enfrentada de maneira diversa daquela que se espera em qualquer outra disciplina, por causa das características que são próprias do filosofar [...] não existe uma Filosofia - como há uma Física ou uma Química - o que existem são filosofias, podendo o professor (a quem chamaríamos de filósofo-educador) privilegiar certas linhas de pensamento e de metodologia, sejam elas a dialética, a fenomenológica, a racionalista, etc.

Além disso, deve ser acrescida a preocupação didático-pedagógica de considerar qual perspectiva teórico-metodológica pode dar conta de enfrentar os desafios de possibilitar um contato produtivo e enriquecedor dos alunos do Ensino Médio, seja no sentido do desenvolvimento das competências e habilidades previstas pelos PCNEM, mas também considerando a pluralidade sócio-cultural dos sujeitos educacionais inseridos num contexto cultural, político, econômico e social contraditório.

Dessa forma, considera-se que uma perspectiva conceitual que pode ser útil para enfrentar os desafios do ensino da Filosofia no século XXI é a de Deleuze e Guattari (1992), que definem a filosofia como "atividade de criação de conceitos". Para esses autores, o filósofo é amigo do conceito, ele é conceito em potência! E os conceitos "não nos esperam inteiramente feitos como corpos celestes. Não há céu para os conceitos. Eles devem ser inventados, fabricados ou, antes, criados, e não seriam nada sem a assinatura daqueles que os criam". (p.13).

Assim, a Filosofia mostra-se como produção, como ato essencialmente criativo, e o filósofo como artesão, como um demiurgo que, da vivência cotidiana produz seus conceitos como pequenas ou grandes obras de arte, que perdurarão por séculos ou serão esquecidos nos porões desabitados (GALLO apud KAHAN, 2002).

Mas, o que é um conceito? Na tradição filosófica pouco se encontra a problematização do conceito, ou a conceituação do conceito. Assim, se o conceito é criação, faz-se necessário saber quais as condições e possibilidades de sua produção.

Pode-se definir o conceito como sendo uma aventura do pensamento que institui um acontecimento, ou vários acontecimentos que permitam um ponto de vista sobre o mundo, sobre o vivido. A ação do conceito permite um reaprendizado do vivido, ou a ressignificação do mundo. Algumas características suas podem ser apontadas. 
Todo conceito vem assinado. Cada filósofo, ao criar um conceito, ressignifica um termo da língua com um sentido particular, propriamente seu. A cada conceito atribui-se um estilo filosófico, uma forma particular de pensar e escrever. Conforme Deleuze e Guattari (1992, p.16), "o batismo do conceito solicita um gosto propriamente filosófico que procede com violência ou com insinuação, e que constitui na língua uma língua da filosofia, não somente um vocabulário, mas uma sintaxe que atinge o sublime ou uma grande beleza." Assim, cada filósofo deixa sua marca no mundo através dos conceitos que cria.

Há outras características do conceito. Todo conceito é criado a partir de problemas já existentes (ou de novos problemas filosóficos, nem sempre fáceis de encontrar), ou de problemas ainda não suficientemente resolvidos. Todo conceito está situado na história e por isso tem uma história. Assim, cada conceito remete a outros conceitos do mesmo filósofo e a conceitos de outros filósofos, constituindo-se de modo nem sempre linear, mas com curvas e idas e vindas, entrecruzamentos. Os conceitos vão, pois, ao infinito e, sendo criados, não são jamais criados do nada.

Um conceito é absoluto e relativo ao mesmo tempo. Relativo, porque remete a seus próprios componentes, aos outros conceitos; relativo aos problemas aos quais se dirige. No entanto, adquire ar de absoluto, pois condensa uma possibilidade de resposta ao problema. Em outros termos, absoluto em relação a si próprio, relativo ao seu contexto. Nas palavras de Deleuze e Guattari (19923, p.34), “um filósofo não pára de remanejar seus conceitos, e mesmo de mudá-los; basta às vezes um ponto de detalhe que avoluma, e produz uma nova condensação, acrescenta ou retira componentes."

Essas e outras características indicam que há um estatuto pedagógico do conceito que delimita as possibilidades de sua criação; uma grande variedade de elementos que ganham sentido com o movimento de articulação que o mecanismo de conceituação promove. Mas há ainda outro item imprescindível para a produção de conceitos. Trata-se da imanência, ou plano de imanência, sobre o qual são gerados os conceitos.

A noção de plano de imanência é fundamental para a criação filosófica, pois o plano é o terreno, o solo, o suporte, o horizonte de produção do conceito. Embora eles não se reduzam um ao outro, e não se confundam, são interdependentes. Os conceitos são acon- 
tecimentos, mas o plano é o horizonte dos acontecimentos. Alguns filósofos criam seus próprios planos; outros conceituam em contexto de planos já delimitados, como os neoplatônicos e os neomarxistas, por exemplo.

Um terceiro elemento deve ser indicado na definição de Filosofia como criação de conceitos: o personagem conceitual. Conforme Deleuze e Guattari (1992), cada filósofo "cria personagens", à maneira de heterônimos, que são os sujeitos da criação conceitual. Assim, em Platão tem-se a figura de Sócrates, que trava os embates com outros personagens. Nietzsche manifesta-se com Zaratrusta, o Anti-Cristo, e assim por diante. Esses personagens conceituais "operam os movimentos que descrevem o plano de imanência do autor, e intervêm na própria criação de seus conceitos." (p. 85).

A Filosofia é, então, constituída por essas instâncias que se inter-relacionam: o plano de imanência a traçar, os personagens filosóficos a inventar, e os conceitos que devem criar. "Traçar, inventar, criar, esta é a trindade filosófica" (DELEUZE; GUATTARI, 1992 p. 101).

Desse modo, a filosofia entendida como produção conceitual não tem a menor pretensão à universalidade e à unidade, muitas vezes buscadas nos tradicionais manuais de Filosofia. Os conceitos são ferramentas que as pessoas utilizam, na medida em que podem ser interessantes para seus problemas. Como afirma Gallo (apud FÁVERO, 2002, p.201), as diferentes filosofias podem ser consideradas como "diferentes óculos, cada um deles nos mostrando diferentes facetas do mundo." Vale ressaltar que não se trata aqui de colocar em disputa qual é a melhor filosofia (o que poderia levar a um certo dogmatismo), mas sim de se buscar apreender a desfrutar produtivamente essa convivência nem sempre tranqüila entre elas.

Acredita-se, portanto, que as idéias acima elencadas podem ser uma alternativa eficaz para os desafios enfrentados no atual contexto sócio-educacional, ainda mais se forem consideradas as mudanças culturais, sociais, econômicas e políticas advindas com a sociedade tecnológica. Tal sociedade foi caracterizada por Deleuze como "sociedade do controle". Se, de um lado, ela traz cada vez mais facilidades à população (em que pese ainda nem sempre o acesso se estender a todos), por outro lado possibilita cada vez mais uma vigilância milimétrica sobre os passos daqueles que nela convivem. Nesse sentido, a escola apresenta-se como uma das instituições de controle 
por excelência. Tal regime de controle alcança não só a materialidade comportamental e somática, como a própria imaterialidade do regime cognitivo, que hegemoniza e mapeia (curricularmente) os saberes considerados apropriados e adequados. Desse modo, a forma como a Filosofia irá ser inserida no cotidiano da vida educacional dos educandos pode ser decisiva para aprofundar sua perspectiva periférica ou para significar um elemento significativo e vivificante na reversão desse quadro, representando uma efetiva contribuição na formação dos discentes. Cabe ressaltar que uma filosofia que não faça sentido para a juventude já foi criticada por muitos filósofos.

Nesse sentido, pensá-la como criação de conceitos pode ser uma maneira interessante de, primeiramente, romper com o imobilismo de certas abordagens tradicionais, muitas vezes pouco produtivas, que reforçam a sua perspectiva periférica ou desinteressante para os alunos. Num segundo momento, também pode significar uma experiência vivificante que possibilita ao educando apossar-se das categorias conceituais filosóficas para dialogar criticamente com os problemas cotidianos do seu tempo e criar alternativas cidadãs de resistência à sociedade de controle. Claro que tal perspectiva não se sucede de modo intempestivo e imediatista. Exige uma mudança na práxis educacional do professor de Filosofia: uma nova perspectiva epistemológica que não se dissocia de um redimensionamento didático-pedagógico. Na prática da sala de aula tudo precisa ser repensado e problematizado: a seleção de conteúdos, materiais didáticos, formas de avaliação e auto-avaliação e a própria relação professor-aluno. Tal mudança acontece simultaneamente em termos desconstrutivos e construtivos, adentrando dialogicamente na perspectiva deleuziana do ensino da Filosofia.

Assim, é necessário desconstruir uma perspectiva enciclopédica que, além de alimentar uma falsa erudição, acaba por não fazer sentido no atual contexto da sociedade da comunicação e informação. Esse processo desconstrutivo também deve se dar em relação a uma filosofia pretensiosamente calcada no "diálogo", em que apenas acaba se proliferando o reino autocrático da opinião que, por si próprio, prescinde de um aprofundamento e diálogo crítico e criativo com os conceitos. Além disso, tal perspectiva - que é muito presente na chamada "filosofia pop" (popularização da filosofia sem muitos cuidados metodológicos) ${ }^{2}$ -

${ }^{2}$ Ver a abordagem interessante de Charles Feitosa sobre o que ele denomina "Filosofia pop". 
acaba reforçando a prática monológica das tecnologias da comunicação e informação que buscam se interpor como representantes da opinião pública. Por fim, uma filosofia baseada na reflexão também tende a se mostrar evasiva, na medida em que se torna um espaço intelectual muitas vezes aberto a elucubrações descompromissadas com um diálogo crítico e produtivo com a tradição filosófica, redundando muitas vezes num discurso panfletário ou proselitista. Como já assinalado acima, tal desconstrução não significa que a Filosofia prescinda da reflexão, comunicação ou contemplação, mas elas precisam ser revivificadas no frenesi criativo e inquietante da produção de conceitos.

Adentrar na perspectiva deleuziana da Filosofia para sua operacionalização didático-pedagógica não é uma tarefa tranqüila. Requer um redimensionamento da centralidade da produção conceitual na tradição filosófica, com todos os seus ingredientes de problematicidade, imanência e percurso dialógico, tenso e denso dos conceitos na produção material dos filósofos. Nesse sentido, a leitura filosófica deixa de ser um mero ato intelectual inconseqüente para tornar-se um encontro e um exercício de atualização e ressignificação conceitual. Em tal exercício, o percurso não está definido previamente, necessita ser construído labirinticamente no embate gerado entre o horizonte social do leitor-filósofo e a imanência discursiva da tradição. As demandas sócio-culturais dos leitores vão, sem dúvida, ter um papel fundamental nesse processo de ressignificação e criação conceitual.

Portanto, contrariamente a um modelo pedagógico que enfatiza a transmissão/ repetição de conceitos, essa "pedagogia do conceito" (Deleuze, 1992, p. 21) requer um diálogo vivo e produtivo do alunoleitor com a tradição filosófica. Trata-se de um processo antropofágico em que os conceitos filosóficos são reapropriados e ressignificados na problematização do cotidiano educacional. Tal perspectiva leva a perceber a disciplina Filosofia no Ensino Médio como atividade criadora que remete para além do clássico debate entre: Filosofia (conteúdo) X o filosofar (processo). Ou seja, tanto o filosofar como a(s) Filosofia(s) devem estar relacionados dialogicamente de modo intenso e produtivo.

Acredita-se que a abordagem pedagógica pode e precisa ser alimentada com outras áreas do conhecimento: as ciências e as artes, em especial. Elas fazem parte de modo vivo e operante dos problemas e questões filosóficas com os quais professores e alunos se defrontam na atualidade. Contudo, não se trata de um diálogo entre saberes distintos, que devem ser mantidos assepticamente no seu espaço 
disciplinar. Trata-se de perceber o quanto as questões filosóficas estão atravessadas por conteúdos de outras áreas e vice-versa. Diante disso, uma perspectiva de uma abordagem transversal de conteúdos que rompa com o regime cognitivo disciplinar torna-se cada vez mais urgente e necessária.

Nesse contexto, a produção do material didático deve pautar-se pela escolha de problemas filosóficos, preferencialmente que sejam significativos existencialmente para os alunos (as pessoas geralmente filosofam a partir dos problemas que sentem na pele). Tais problemas devem ser devidamente municiados com obras filosóficas, referenciais históricos da filosofia e também com saberes das outras ciências e/ ou produções culturais audiovisuais (textos literários, jornalísticos, filmes, documentários) que ajudem a ressignificar e explorar as múltiplas faces da questão problemática. Tem-se, por exemplo, obras que constituem uma rica produção cultural literária e audiovisual, muitas delas já fazendo parte da subjetividade da maioria dos educandos, que trazem uma gama de questões filosóficas a serem exploradas. Alguns autores de Filosofia, como Juan Antonio Rivera (2004), são exemplos das possibilidades fecundas desse entrecruzamento. Escolhe o autor produções cinematográficas que trazem elementos de reflexão dos vários campos da filosofia, que vão desde Cidadão Kane, até Matrix, Blade Runner, etc. Indica também obras literárias como 1984 e $A$ revolução dos bichos (George Orwel), A metamorfose e $O$ processo (Franz Kafka); acrescente-se ao autor a ousadia de inserir clássicos da literatura brasileira como Memórias póstumas de Brás Cubas (Machado de Assis), Angústia (Graciliano Ramos) e tantos outros que podem ser extremamente produtivos para o trabalho interdisciplinar da Filosofia.

Em relação às competências e habilidades específicas da Filosofia, sugere-se uma linha teórico-metodológica que privilegia muito mais "cabeças bem feitas" do que "cabeças cheias", parafraseando o filósofo Montaigne. Assim, a experiência da atividade filosófica (criadora de conceitos) pode propiciar aos educandos muitas das competências e habilidades necessárias para o convívio cidadão, crítico e engajado numa sociedade plural e em constante transformação.

Dessa forma, as competências estabelecidas pelos PCNEM+ podem ser ressignificadas com a perspectiva teórico-metodológica enfatizada até aqui. A título de exemplo, apresentam-se a seguir algumas sugestões bastante úteis para o trabalho pedagógico. 
Problematizando os PCNEM+ para a atividade docente de Filosofia

Assim, no tópico que enquadra a competência de Representação e Comunicação na atividade filosófica são indicados ${ }^{3}:$ 1) Ler textos filosóficos de modo significativo. 2) Ler, de modo filosófico, textos de diferentes estruturas e registros. 3) Elaborar por escrito o que foi apropriado de modo reflexivo.

O primeiro item sugere, evidentemente, a necessária referência de textos filosóficos e seus autores. O importante é não perder de vista os diferentes graus de problematicidade que possibilitam a ressignificação a partir do cotidiano existencial dos alunos. Tal leitura, bem orientada e motivada, pode possibilitar um incremento significativo no processo de autonomização crítica do pensar.

O segundo item sugere que os problemas filosóficos podem e devem ser alimentados com outras ciências ou ainda outros produtos culturais e audiovisuais, como já acenado no corpo da primeira parte do texto. A própria natureza dos problemas filosóficos acaba remetendo ao exercício interdisciplinar ou, melhor ainda, ao exercício transversal de conteúdos.

O terceiro remete à produção textual, prática já bastante conhecida, mas por vezes marcada por certo engessamento ou aversão. A escrita pode acontecer em diversos momentos, como sistematização dos problemas filosóficos, dos debates gerados a partir desses problemas, das relações transversais e interdisciplinares surgidas e, ainda, como uma dissertação que traduza o percurso filosófico do aluno na abordagem dos problemas. É importante lembrar que em alguns casos, quando as instituições permitem e dão condições, a elaboração de produtos audiovisuais é perfeitamente válida.

Problematizadora e criadora de conceitos, a atividade filosófica requer que os alunos exerçam continuamente a capacidade de argumentação e interlocução crítica, aprimorando assim a luta contra o mundo da opinião (doxa, como diria Platão). Nesse sentido, o filosofar irá exigir a construção de argumentos cada vez mais consistentes e fundamentados, que precisarão passar pelo crivo crítico de interlocutores cada vez mais atentos. Para tal intento, torna-se cada vez mais necessário um exercício interdisciplinar que possa municiar a interlocução. No entanto, esse exercício não pode ser inspirado numa busca dogmática pela verdade (tão presente nos diferentes discursos,

${ }_{3}^{3}$ O leitor poderá consultar o texto original com as especificações dos PCNEM+. Os comentários seguintes são dos autores deste texto. 
sejam científicos, políticos ou midiáticos, dentre outros), mas deve ser pautado sempre pelo contato com a diversidade de perspectivas e a complexidade do mundo. Tal exercício interlocutório, sem dúvida, pode ser precioso no desenvolvimento das competências relacionadas com uma cidadania ativa, crítica e produtiva.

$\mathrm{Na}$ competência dos PCNEM+ denominada Investigação e Compreensão está registrado o seguinte objetivo: "Articular conhecimentos filosóficos e diferentes conteúdos e modos discursivos nas Ciências Naturais e Humanas, nas Artes e em outras produções culturais". Como já se salientou neste texto, a atividade filosófica precisa, de fato, ser alimentada com outros saberes da arte e das ciências, além das demais produções culturais. Vale ressaltar que o contrário também é necessário, para que tais conhecimentos não sejam apreendidos de forma dicotômica e disciplinar. Na efervescência de informações e comunicações atualmente vivenciadas, propiciadas pelas novas tecnologias, torna-se necessário desenvolver uma capacidade de garimpagem, seleção e interpretação das informações que possibilitem uma articulação produtiva e significativa dos saberes. Não há dúvida de que, nesse caso, a atividade filosófica pode ser um auxiliar precioso para enfrentar o "caos" e perceber as diversas perspectivas e inter-relações que conduzem a novos saberes.

Na competência dos PCNEM+ denominada Contextualização Sócio-Cultural propõe-se "Contextualizar conhecimentos filosóficos, tanto no plano de sua origem específica, quanto em outros planos: o pessoal-biográfico; o entorno sócio-político, histórico e cultural; o horizonte da sociedade científico-tecnológica". Entende-se, realmente, que o filosofar faz parte da vida cotidiana do ser humano, na medida em que ele se depara existencialmente com a necessidade de problematizar seus valores, suas escolhas, sua subjetividade e, enfim, seu existir. Portanto, para que o filosofar possa fazer sentido aos alunos é fundamental a sua relação com o cotidiano. Desse modo, os problemas filosóficos devem ser continuamente ressignificados pelas vivências pessoais, sociais, políticas e culturais. Trata-se, sem dúvida, da "alma" da atividade filosófica: ela precisa dialogar com os seus leitores para se tornar viva e levar à produção de novos significados. Os problemas pessoais, locais, regionais, globais e históricos vivenciados cotidianamente devem estar presentes no horizonte da atividade filosófica. $\mathrm{O}$ embate filosófico deve propiciar um contato dialógico com tais problemas, seja para questioná-los, repensá-los ou redimensioná-los, levando a novos posicionamentos e atitudes. 
Problematizando os PCNEM+ para a atividade docente de Filosofia

O texto dos PCNEM+ propõe, ainda, Eixos Temáticos (conteúdos) a serem trabalhados nas séries do Ensino Médio. Essa é uma questão que precisa ser problematizada a partir da prática pedagógica dos educadores e dos respectivos contextos sócio-educacionais, e que permanece aberta para pesquisas e outras contribuições.

\section{CONSIDERAÇÕES FINAIS}

O debate sobre o ensino e a aprendizagem de Filosofia vem carregado de paradoxos e desafios. Desafios de sensibilizar estudantes que vivem em uma sociedade difícil e complexa, denominada de diferentes formas, mas cujas características determinantes são a tecnologia, a velocidade de informações, a massificação, a autocracia da eficiência e do controle, que freqüentemente sufocam o cronos heterogêneo e diferenciado exigido pelo filosofar.

A partir do contexto pedagógico centrado nas competências e habilidades, os PCNEM e sua versão + intentam estabelecer alguns pontos referenciais sobre as finalidades, objetivos, metodologias da atividade filosófica no espaço-tempo escolar. Com base em sua práxis educacional, formação profissional e horizonte biográfico-existencial, cabe ao educador-filósofo estabelecer um diálogo crítico com tal perspectiva. Mas, para que esse diálogo seja produtivo, torna-se necessário problematizar a concepção de Filosofia na qual está inspirada a atividade docente.

Nesse sentido, a perspectiva deleuziana pode ser fecunda para problematizar as práticas pedagógicas do ensino de Filosofia e ressignificar dialogicamente os PCNEM, buscando estabelecer indicativos didático-pedagógicos que consigam enfrentar os desafios contemporâneos. Assumir a Filosofia como atividade criadora de conceitos leva a questionar práticas tradicionais centradas num pretenso "diálogo, reflexão e comunicação", e a exigir uma postura que propicie o encontro dialógico, vivo, tenso e denso dos estudantes com a tradição filosófica. Essa perspectiva possibilita ressignificar a relação professor e aluno em sala de aula. O aluno, longe de um papel passivo e descompromissado, é desafiado a também tornar-se "criador de conceitos", a modo próprio, devendo exercer ativamente suas capacidades de leitor, produtor de textos escritos e audiovisuais, entre outras, e desenvolver sua autonomia crítica e comprometida com o contexto social e político. 
Para dinamizar a referida perspectiva, é fundamental mobilizar o entorno sócio-cultural que povoa o horizonte social do estudante: a cultura audiovisual, as ciências, as artes, etc. $O$ papel do professor de Filosofia é fundamental na medida em que ele deve perceber artesanalmente, no encontro dialógico com seus alunos, que estratégias de aprendizagem podem ser significativas para o exercício filosófico de criação de conceitos. Assim, longe de uma prática pedagógica monológica e vertical, a atividade pedagógica filosófica implica uma experiência única com a diversidade do cotidiano e com a intempestividade e imprevisibilidade como movimentos da aprendizagem.

\section{REFERÊNCIAS}

BRASIL Ministério da Educação. Parâmetros Curriculares Nacionais para o Ensino Médio. Brasília: Secretaria de Educação Média e Tecnológica (Semtec, MEC), 1999.

Parâmetros Curriculares Nacionais para o Ensino Médio+. Brasília: Secretaria de Educação Média e Tecnológica (Semtec, MEC), 2006.

COMTE SPONVILLE, A. A filosofia. São Paulo: Martins Fontes, 2005.

DELEUZE, G.; GUATTARI, F. O que é a filosofia? Rio de Janeiro: Ed. 34, 1992.

FEITOSA, C. O que é isto - filosofia pop? In: LINS, Daniel (Org.). Nietzche e Deleuze: pensamento nômade. Rio de Janeiro: Relume Dumará, 2001.

GALLO, S. Filosofia no Ensino Médio: em busca de um mapa conceitual. In: FÁVERO, A. A. et al (Orgs.). Um olhar sobre o ensino de filosofia. Ijuí, RS: Editora da Unijuí, 2002.

. Filosofia e educação: pistas para um diálogo transversal. In: KOHAN, W. O. (Org.). Ensino de Filosofia. Belo Horizonte: Autêntica, 2002.

RIVERA, J. A. O que Sócrates diria a Woody Allen. São Paulo: Planeta do Brasil, 2004.

Encaminhado em: 03/07

Aceito em: 11/07 